Euskal ikerketen aldizkaria | Revue d'études basques |

Revista de estudios vascos | Basque studies review

$11 \mid 2006$

Numéro XI

\title{
Las citas de Aristóteles en Axular
}

\section{Elena Redondo Moyano}

\section{OpenEdition}

\section{Journals}

\section{Edición electrónica}

URL: http://journals.openedition.org/lapurdum/432

DOI: 10.4000/lapurdum.432

ISSN: 1965-0655

Editor

IKER

Edición impresa

Fecha de publicación: 1 noviembre 2006

Paginación: 311-331

ISBN: 978-2-86781-474-7

ISSN: $1273-3830$

\section{Referencia electrónica}

Elena Redondo Moyano, « Las citas de Aristóteles en Axular », Lapurdum [En línea], 11 | 2006

Publicado el 01 abril 2008, consultado el 30 abril 2019. URL : http://journals.openedition.org/ lapurdum/432 ; DOI : 10.4000/lapurdum.432 


\title{
Las citas de Aristóteles en Axular ${ }^{1}$
}

\author{
Elena REDONDO MOYANO \\ E.H.U.
}

Axularren garaian autore klasikoen aipuak tartekatzea ohiko konposaketa bidea zen. Baina aipu horiek aldaketa ugari pairatzen zituzten garaiko testu berrietan egokitzeko. Lan honetan Aristotelesen aipuak aztertzen ditugu jasotako aldaketak agerian uzten ditugularik.

En el año 1643 salió a la luz pública en Burdeos la única obra de Pedro de Axular (1556-1644), Después, escrita en los últimos años de su vida en Sara, donde ejerció como párroco desde el año 1600. Tanto el título de la obra como las primeras palabras que Axular dirige a sus lectores ("Irakurtzailleari", 6, p. $13^{2}$ ) explican el tema de que trata, el daño que hace a las almas y a los cuerpos el dejar para después, el diferir o aplazar las obligaciones. Este tema se trata a lo largo de 18 capítulos; el resto del libro, otros 42 capítulos $^{3}$, es una llamada al cumplimiento de las normas morales que debe abrazar, sin más tardanza, el buen católico. Después es una obra con claro afán pedagógico y apologético, surgida en el marco de la historia religiosa del momento: para los calvinistas del siglo XVII el trabajo había llegado a ser no ya la única manera cristiana de gastar el tiempo de vida que Dios había concedido, sino que el éxito profesional era considerado una prueba de estar en posesión de la gracia de Dios. Era por tanto un asunto de gran importancia para la Iglesia de la Contrarreforma por un lado el replantear el tema del trabajo desde la óptica católica, especialmente en Navarra, donde el calvinismo había tenido una gran difusión en la segunda mitad del siglo XVI de la mano de Juana de Albret $^{4}$; y por otro explicar con claridad a la población ${ }^{5}$ el modo de vida que un católico debía llevar y prevenirle del sufrimiento eterno que le acarrearía el desviarse de este camino, dibujándole con viveza en los últimos 5 capítulos la configuración

1 - Este trabajo ha sido realizado dentro del PI EHU 06/109. Quiero agradecer a mis compañeras de proyecto, Guadalupe Lopetegi y Maite Muñoz, así como a mis colegas de Departamento, Iñigo Ruiz Arzallus y Gidor Bilbao la ayuda prestada para recopilar la bibliografía necesaria para realizar este trabajo. 2 - Las citas corresponden al capítulo (en este caso el prólogo, "Irakurtzailleari"), al parágrafo y página de la edición de Villasante, 1976. De esta misma obra están tomadas también todas las traducciones al castellano que aparecen en este artículo.

3 - Sobre la estructura del libro y las dos partes que se anuncian en el título cf. Orpustan, 1996, 53-55.

4 - La conciliación que se da en Después entre los dos movimientos religiosos, el reformista y el contrarreformista, no está sin duda muy distante de la que defendió el jansenismo.

5 - Orpustan, 1996, 55-57, pone de relieve que Axular se sirve de todo tipo de procedimientos a su alcance para hacer su mensaje eficaz, desde la propia articulación del trabajo, claramente organizado en unidades racionales que se desarrollan en capítulos concretos, hasta la utilización de un arte de contar que se apoya en ejemplos de la vida natural o cotidiana y un tono de conversación confidencial propio del predicador que habla a uno de sus feligreses. 
geográfica y temporal del "después" que en tal caso le esperaba, el infierno ${ }^{6}$. El libro contiene, por tanto, un claro mensaje propagandístico de la Iglesia católica, la cual, tras el Concilio de Trento (1545-1563), había decidido contraatacar con determinación los movimientos reformistas. Para ello no dudó en servirse de algunas de las estrategias que los propios reformistas habían utilizado, como la de predicar al pueblo en su lengua vernácula; de ahí que Axular explique en su prólogo que, estando en buena compañía ("Irakurtzailleari", 6, p. 13, "konpaiñia on batean") -es decir, con toda probabilidad, en compañía de otros religiosos contrarreformistas de su época ${ }^{7}$ - la conversación trató de la necesidad de difundir el tema del libro entre la población que sólo sabía vasco. Este dato sólo puede significar que la gran mayoría de la población hablaba en esta lengua y sólo en ella, de manera que era el único vehículo por el que podía hacérsele llegar el mensaje religioso que las autoridades eclesiásticas católicas querían difundir ${ }^{8}$. Dado que un poco más adelante Axular afirma que dirige su libro a lectores poseedores de alguna cultura ("Irakurtzailleari", 11, p. 17, "Eztut liburutto haur letratu handientzat egiten. Eta ez xoil, deus eztakitenentzat ere" ), Oyharçzabal ha supuesto que el público al que Axular se dirigía estaba constituido por gentes que habían accedido a una formación básica en su lengua nativa ya fuera en sus parroquias, ya fuera por medio de clases particulares en sus localidades de origen, dado que no existía todavía ninguna institución escolar colectiva. Esta formación estaría directamente relacionada con el aprendizaje de oraciones y la comprensión, en general, del mensaje religioso, que estaba escrito en latín, la lengua de cultura tradicional y la única admitida para los textos religiosos por la iglesia católica, la cual, a diferencia de los reformistas, había prohibido su traducción a las lenguas vernáculas, como modo de impedir que su interpretación estuviera al arbitrio del lector particular y quedara siempre en manos de la Iglesia y sus ministros. Estas especiales circunstancias socio-religiosas favorecieron una diglosia latin vs vasco e hicieron necesaria para los vascófonos monolingües una lengua escrita para su formación religiosa ${ }^{10}$. Axular, y veinte años antes Materre, dirigían sus mensajes religiosos a una población vascoparlante y con alguna instrucción en letras ${ }^{11}$, que tendría acceso

6 - Sobre la imagen del infierno que transmite Axular trata el sugerente artículo de Arcocha-Scarcia, 1996; el título de la obra es, como la autora apunta (101), polisémico.

7 - Cf. Villasante, 1976, 12, nota 4, donde se menciona a los franciscanos Materre y Aramburu, y a Bertrand d'Etchauz, obispo de Bayona y arzobispo luego de Tours, un firme conductor de la aplicación de las consignas del Concilio de Trento, que fue quien nombró a Axular párroco de Sara; a él precisamente le dirige su "Gomendiozko Karta" o Carta (póstuma) de Recomendación que aparece en Después.

8 - Efectivamente, como Oyharçabal, 2001, 6, apunta a comienzos del siglo XVII el vasco era la lengua de comunicación de las tres provincias vascas del norte; sobre el estatus de esta lengua y su relación con el francés y el latín cf. especialmente el apartado "Le lectorat des écrits labourdines du $17^{\circ}$ siècle", pp. 6-13. 9 - "No hago este librito para personas muy cultas. Ni tampoco para los que no saben absolutamente nada."

10 - Cf: Oyharçabal, 2001, 11-13, 22 y 46. Esta modalidad diglósica cederá paso paulatinamente a la del vasco vs francés (tras la coronación de Enrique IV en 1599 como rey de Francia y de Navarra la frontera franco-española se estableció tal como existe en la actualidad), a medida que esta última lengua, que siempre fue la utilizada en el ámbito judicial y en las altas esferas del poder, se fue extendiendo a otras capas de la población distintas de las más elevadas, que siempre habían tenido acceso a una educación más amplia y ocasión de salir del país.

11 -Por ello, Axular puede explicar a sus lectores determinadas opciones gráficas por las que se ha decidido para representar sonidos del vasco, como en 9, 15, donde apunta: "eskiribatze hunen gaiñean,..., nola latinak bi $i$ eta bi $v$ egiten baititu bat eta hartzen batentzat ... Eta espaiñolak ere bi $l$ egiten baititu bat, ..., hala euskarak ere bi $t$ egiten dituela bat" ("Respecto a este asunto de la grafía, ..., así como el latín une dos "i" y dos "v" tomándolas por una ... y también el español une dos "l" haciendo de ellas una ... así también el euskera une dos " $t$ ", haciendo de ellas una.") 
directo a estos textos, si bien no hemos de olvidar que las lecturas en voz alta, dirigidas a colectivos diversos, eran todavía frecuentes en el siglo XVII ${ }^{12}$, por lo que el mensaje podría tener una difusión más amplia.

Junto al vasco en que la obra estaba redactada, el lector de Después se encontraba con numerosas citas en latín extraidas de textos religiosos y de determinados autores paganos o "gentiles" ${ }^{13}$. Efectivamente, desde el redescubrimiento de los clásicos en el Renacimiento, se revitalizó o se generalizó la práctica de la mención de éstos o la inclusión de partes de su obra en los nuevos textos que se generaban. Este procedimiento fue adoptado también por la Iglesia, que ya utilizaba como medio de ilustrar sus mensajes la cita de pasajes bíblicos u otros textos religiosos. Así, Fray Luis de Granada recomendaba para la inventio, o proceso de búsqueda de los materiales con los que componer un discurso o un texto en general, seguir estos pasos: "Primeramente pues debe juntarse mucho y vario caudal de cosas, que sugerirá la varia lección, así de nuestros autores (sobreentiéndase "cristianos"), como también de los gentiles. A lo cual ayudan maravillosamente, no solo las sentencias, sino también los ejemplos, los símiles y los apotegmas." ${ }^{\text {. }}$. Patxi Salaberri, tras estudiar estas citas, llega a la conclusión de que las de carácter religioso son exactas en general, lo cual puede considerarse indicio de que fueron tomadas directamente de los textos citados, o bien que, en caso de tomarlas de otros lugares, Axular tuvo ocasión de comprobarlas en los textos originales ${ }^{15}$. Por el contrario, tras el examen de las citas, menciones y exempla tomados de diversos autores clásicos -Séneca, Ovidio, Horacio, Plutarco, Aulo Gelio y Juvenal-, concluye, como ya antes había apuntado Lafitte, que lo más probable es que Axular no las tomara directamente de los autores clásicos, sino de alguna fuente intermedia ${ }^{16}$. Y en este aspecto, también, Axular se muestra como un hombre de su tiempo. Es bien sabido por los estudiosos de obras de los siglos XVI y XVII ${ }^{17}$ que en las escuelas humanísticas, siguiendo prácticas anteriores ${ }^{18}$, la lectura de los textos clásicos iba acompañada del apunte de aquellos pasajes breves que, bien por su forma, bien por su contenido, pudieran considerarse modélicos y, por tanto, dignos de ser imitados y citados en otros contextos. De este modo, todo aquello que se consideraba digno de ser recordado se apuntaba agrupándolo por materias y el procedimiento estaba tan extendido que eruditos como Erasmo, Luis Vives, Miguel de Salinas, Lorenzo Palmireno y Justo Lipsio dan instrucciones concretas sobre cómo realizar este trabajo con eficacia. Por otro lado, ya desde la Edad Media, para la confección de discursos teológicos era habitual apoyarse en colecciones (flores,

12 - Que quienes sabían leer lo hicieran en voz alta para otros es una costumbre documentada desde la Antigüedad que se pervivió prácticamente hasta el siglo XX; cf. Mangel, 2005, passim y para el siglo XVII, p. 174.

13 - Cf. Salaberri, 1997, 282-283.

14 - Cf. Retórica Eclesiástica o de la manera de predicar, in Obras del V. P. M. Fray Luis de Granada, III, 1945, 611a.

15 - Cf. Salaberri, 1997, 269-270. No obstante, en Axular como en otros autores de la época aparecen algunos errores, cuyo origen no es fácil averiguar, ya que puede tratarse de fallos del autor a la hora de citar, o bien fallos que existían ya en fuentes distintas -como comentarios o exégesis de determinados pasajes- que Axular pudo utilizar, de manera que él no habría hecho más que trasladarlos a su texto sin comprobarlos, o bien pueden deberse al editor o al impresor.

16 - Cf. Salaberri, 1997, 282-303 y Lafitte, 1943, 38-39.

17 - Los datos que aquí exponemos están sacados del útil artículo de López Poza, 1990, 61-62, donde se apunta una bibliografía relativa a sentencias y polianteas basada en los catálogos de la Biblioteca de la Universidad de Santiago de Compostela, los de la biblioteca de Universidad Complutense de Madrid y la Biblioteca del Monasterio de Poyo (Pontevedra).

18 - Cf. Hamesse, 1974, 9: "Le genre littéraire des florilèges est bien antérieur au XIII" siècle. On trouve dès l'Antiquité des recueils d'Auctoritates. Il suffit de rappeler la littérature doxographique, les nombreux florilèges contenant des extraits d'auteurs latins classiques ainsi que des Pères de l'Église." 
thesaurus) que recogían el pensamiento de ilustres exégetas religiosos (San Agustín, San Gregorio Magno....) o pasajes de la Biblia o incluso algunas obras de autores paganos (Jenofonte, Flavio Arriano, Apuleyo) cuyo mensaje no entraba en contradicción con la ortodoxia religiosa. La difusión de la imprenta puso en manos de todos aquellos que no tenían posibilidad de acceder a los textos religiosos o clásicos -hombres cultos o curiosos de los siglos XVI y XVII, escritores, predicadores ${ }^{19}$ - estas colecciones que podían ser utilizadas ya como medios para el cultivo personal, ya como fuentes de citas que ilustraran sus obras con las funciones de probar lo que anteriormente se había dicho (probatio) y de adornar (ornatus) el pasaje, a la vez que se divulgaba conocimiento (docere) sin dejar de lado el placer estético (delectare). El uso de estas colecciones en la literatura de estos siglos, tanto en autores paganos ${ }^{20}$ como cristianos, se convirtió en un procedimiento de trabajo $^{21}$, que no implicaba que el escritor hubiera leído las obras que citaba, al igual que tampoco permitía deducir lo contrario, y como tal era aceptado igualmente por los lectores. La utilización de este procedimiento compositivo fue en aumento y en el siglo XVII llegó a ser tan abusivo que algunas voces se levantaron para denunciarlo ${ }^{22}$.

Por otro lado, la lectura directa de los clásicos había sido también limitada por la Iglesia de la Contrarreforma ${ }^{23}$ : su lectura se permitía en tanto que el lector no se familiarizara excesivamente con estas obras, no fuera que los pensamientos en ellas contenidos se materializaran en obras; de ahí que lo preceptivo fuera tomar de ellas únicamente aquello que se tuviera buen acomodo dentro la ortodoxia cristiana. Los poetas debían ser mencionados poco, sólo cuando se encontrara en ellos alguna sentencia muy breve y realmente notable, y de los filósofos estaba permitido citar sólo aquello que tuviera relación estrecha con el tema que se trataba, y cuidando siempre de dejar en evidencia que la fe y las tradiciones religiosas quedaban por encima de la interpretación racionalista que de ellos se pudiera desprender ${ }^{24}$. Si a estas restricciones impuestas por la Iglesia católica añadimos la dificultad material que se daba para conseguir los libros de los clásicos, no es de extrañar que en el siglo XVII, en el que funcionaba una estricta censura eclesiástica ${ }^{25}$, las citas de los clásicos se tomaran de colecciones o de otras obras donde su uso las hubiera sancionado como adecuadas a la ortodoxia. Así, por ejemplo, muchas de las citas de Séneca que aparecen en Después se encuentran tanto en las colecciones de silva o loci, como en autores cristianos en general (Padres de la Iglesia, teólogos o tratadistas). De hecho, el propio Axular, tras el título, deja constancia de que ha recopilado su obra "Eskritura Saindutik, Elizako doktoretarik eta liburu

19 - López Poza, 1990, 63, menciona colecciones especializadas para predicadores que fueron utilizadas por Fray Luis de Granada o Tomás de Trujillo.

20 - Cf. Ruíz Arzallus, 1996, 265-284, donde se descubre el repertorio que fue utilizado en la La Celestina primitiva para citar todas las sentencias de Aristóteles, Séneca, Boecio y el pseudo Boecio que en esta obra aparecen. En este artículo se encuentra, igualmente, una interesante bibliografía sobre las colecciones de citas de autores antiguos.

21 - Cf. Ruíz Arzallus, 1996, 283.

22 - Es el caso del jesuita José de Ormaza, que cita López Poza, 1990, 64.

23 - Cf. Salaberri, 1997, 282-283.

24 - Axular debía ser un buen conocedor de estas normas, ya que fue uno de los examinadores que declaró aptas, por no contravenir la fe cristiana, obras de Materre (Dotrina Christiana) y de Etxeberri de Ziburu. De este dato se desprende, también, que Axular gozó de una posición relevante dentro de la diócesis de Bayona, uno de los principales focos de defensa de la ortodoxia católica; cf. Urquizu, 2000, 198 y Harischelhar (prólogo a la traducción de Luján), 2001, 16.

25 - Es precisamente en los comienzos del XVII cuando tuvieron lugar los procesos contra la brujería que padeció Lapurdi; cf. Urkizu, 2000, 161-162. 
debozinozkoetarik", es decir, de las Sagradas Escrituras, de los doctores de la Iglesia y de los libros de devoción ${ }^{26}$.

En este trabajo nos proponemos estudiar la forma en que los textos clásicos eran alterados para ser adaptados a las concepciones estéticas y éticas que exigían las obras compuestas en la época contemporánea a Axular. Vamos a estudiar un caso concreto, el de Aristóteles, cuyos textos originales vamos a confrontar con las referencias que a ellos se hacen en Después. Es sabido que la obra del estagirita había sido bien conocida y estudiada durante la Edad Media, en concreto a partir del siglo XII, en el que fue traducida del griego y del árabe al latín; desde entonces fue un autor de prestigio que se enseñaba en los medios universitarios ${ }^{27}$. Axular cita cuatro libros de Aristóteles, la Política, la Ética, Sobre el alma y la Física ${ }^{28}$. En el facsímil de Después Aristóteles, como otras autoridades religiosas o paganas, aparece citado por su nombre ("Erraiten du Aristotelek" (1, 15, p. 23 y 9, 78, p. 129), "Halatan erraiten du Aristotelek" (7, 62, p. 99; 33, 235, p. 401 y 38, 249, p. 425), "Erran beza Aristotelek" (12, 102, p. 171), y en el margen de la línea en la que tal nombre aparece se encuentra la mención del libro y, a veces, el capítulo de donde ha sido tomado el pasaje en cuestión. En la única edición que en el siglo XX se publicó de Después, la de Villasante, estas referencias están incluidas en el texto entre paréntesis y sucede lo mismo en la traducción al castellano que le acompaña. En la otra traducción a una lengua actual que tenemos a nuestra disposición, la de Luján al catalán, se apuntan esas referencias en notas al pie de página. Las menciones de Aristóteles tienen las mismas formas que las del resto de los autores, con tres variantes:

a) Cuando existe cita de sus palabras, como en el caso de la Ética, de Sobre el alma y de la segunda cita del libro V de la Política, esta cita se hace en latín y a continuación se encuentra su traducción al vasco o unas palabras que explican su contenido.

b) En otras dos citas, las dos primeras que aparecen de la Política, sólo se menciona el contenido del pasaje, pero no aparece texto alguno.

26 - La crítica moderna ha encontrado, efectivamente, similitudes entre la obra de Axular y la de otros autores religiosos que se leían en su época. El primero en detectar similitudes entre la obra de Axular y Fray Luis de Granada fue Urquijo, 1912; le siguió Villasante, 1972, 136-155; Mitxelena, 1971, señaló coincidencias con Alejo Benegas; Salaberri, 1997, en su Eranskina confronta pasajes de Axular con los de otros autores (Leizarraga, Materre, Fray Luis de Granada ...) de temática similar y en su Axularren bistoriak, 1998, publicó los exempla profanos que aparecen en la obra de Axular presentándolos como similares a los que aparecen en otros autores de la época en lenguas diversas (p. 9). En Aldekoa, 2004, 51, podemos leer: "La revelación de la Sagrada Escritura, los comentarios y dichos por los doctores de la Iglesia y los libros de devoción son las grandes fuentes de la que bebe el escritor de Urdax y párroco de Sara"; en concreto, en 53, se apuntan dos libros de Fray Luis de Granada, la Guía de pecadores y De la oración y meditación, como fuentes de las que tomó numerosas citas, reflexiones y ejemplos de autores de la Antigüedad. El mismo método de trabajo utilizó a principios del siglo XVIII Joanes Etxeberri de Sara; las fuentes y las estrategias de composición en que se basó para componer su obra han sido estudiadas por Gidor Bilbao, 1996; cf. también la útil bibliografía que en este trabajo se menciona. 27 - Cf. Hamesse, 1974, 7-9.

28 - En la traducción de Después de Fr. Pedro Antonio Añibarro (citamos esta obra por la edición de Blanca Urgell, 2001) aparecen estas mismas menciones de la obras de Aristóteles, pero con las siguientes diferencias: (1) las citas en latín, las aristotélicas y prácticamente todas que aparecían en el libro de Axular (cf. p. CLXXXVII), han desaparecido y ha quedado sólo su traducción; así sucede en 7.82-83, p. 110 (Axular, 7.62, p. 99) y 9.114, p. 146 (Axular, 9.78, p. 129). Otras veces, cuando no existía en Axular cita en latín, ha desaparecido en Añibarro la cita de la obra de Aristóteles de la que han sido tomadas, como en 1.77, p. 23 (Axular, 1.15, p. 23), 32.60, p. 367 (Axular, 33.235, p. 401) y 36.8, p. 385 (Axular, 38.249, p. 425). Un caso especial es 12.27, p. 193 (Axular, 12.102, p. 171; ver nota referida a esta cita), en el que se da en Axular el texto en latín sin traducir, y en Añibarro únicamente el lugar donde aparece. 
c) Por último, en la cita de la Física, aparece el texto latino copiado en el margen y $\sin$ traducir $^{29}$.

\section{Las citas de la Política, la Ética y Sobre el alma.}

Cinco de las seis veces que Axular cita a Aristóteles lo hace para fundamentar algo que está exponiendo, es decir, lo utiliza como autoridad. Tres de ellas pertenecen a La Política, que es el libro más citado en Después. El título de esta obra en griego, Politiká $a^{30}$, es el neutro plural del adjetivo politikós, de manera que significa "lo relativo a la pólis" o ciudad-estado. La obra trata, efectivamente, de temas concernientes a la organización política del estado y está dividida en libros en los que se trata monográficamente sobre un tema importante. En la obra de Axular se citan el libro II y el V de la Política. En el libro II Aristóteles analiza cuál puede ser la mejor constitución o sistema político para gobernar el estado. Se encuentra organizado en tres partes, una primera (1-8) en la que se analizan las constituciones teóricas que eran consideradas como las mejores -la que Platón expuso en su República y en Leyes, la de Faleas de Calcedonia y la de Hipodamo de Mileto-; una segunda (9-11) en la que se hace un análisis crítico detallado de constituciones que en vida de Aristóteles estaban en vigor, como la de Esparta, Creta y Cartago, y una tercera (12) en que se trata brevemente de legisladores legendarios como Licurgo y Solón. La cita que Axular hace aparece en la segunda parte, concretamente en el examen de la constitución de los lacedemonios o espartanos (9). Aristóteles procede metódicamente en ese examen y comienza señalando los puntos débiles que en su opinión tiene esta organización estatal: el primero es que, para tener cubiertas las primeras necesidades, los lacedemonios se sirven de los ilotas, una población sometida que se rebela continuamente contra ellos. El segundo es la libertad y poder que en tal constitución tienen las mujeres:

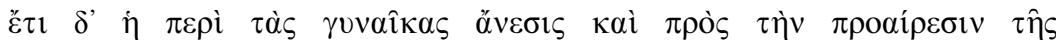

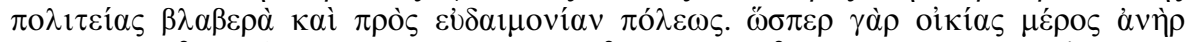

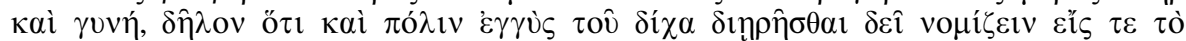

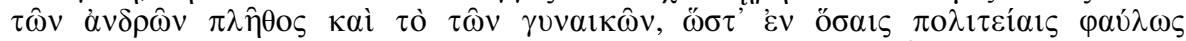

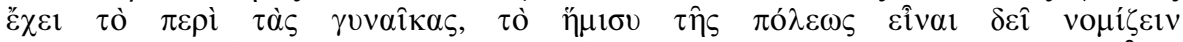

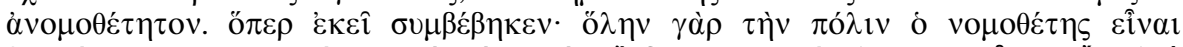

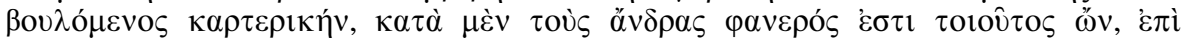

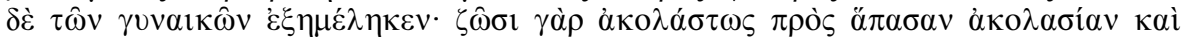

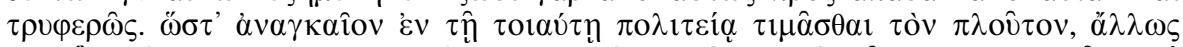

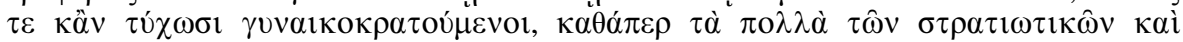

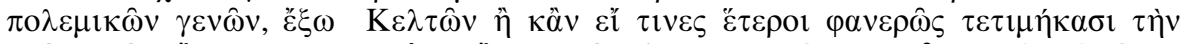

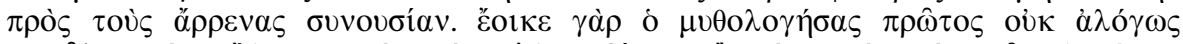

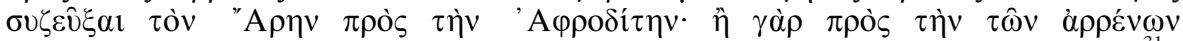

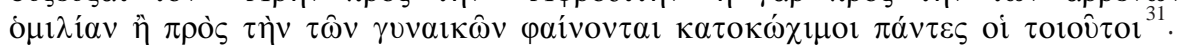

29 - Así se puede apreciar en la edición facsímil de Euskaltzaindia, 1988, p. 154. Villasante, 1976, 171, en cambio, introduce la cita latina en el cuerpo del texto, entre paréntesis y Luján, 2001, 125, apunta cómo se encuentra la cita en una nota.

30 - Los datos de esta obra que aquí exponemos los hemos recogido de la Introducción a la Política realizada por García Valdés, 1988.

31 - "Además, la licencia de las mujeres es perjudicial tanto para el propósito del régimen como para la felicidad de la ciudad. Pues así como el hombre y la mujer son parte esencial de la casa, es evidente que 
Este pasaje del libro II de la Política aparece citado en el capítulo 33, 235, p. 401, en el siguiente contexto:

234. (Comienzo de 33, p. 399) "Amorio desordenatuak hanbat kalte egiten du, non behin hark itsutuz gero, amoltsu eta bakezko zirenak ere, egiten baititu anhitzetan bere desiren konplitzeagatik, traidore, bihotz gogor, cruel, eta erhaile." ${ }^{32}$ Una vez que ha expuesto esta tesis, Axular la revaloriza citando varios ejemplos de autoridades que funcionan como pruebas de lo que acaba de decir. Los primeros están sacados de escritos religiosos, de la Biblia (el del rey David) y de la hagiografía (el de fray Guerin y el de Santiago el penitente); Axular cierra esta primera sección de citas del ámbito religioso argumentando que si tales personajes pecaron por influencia de ese amor desordenado, en mucho mayor peligro de hacerlo se encuentran quienes no son tan virtuosos como ellos. Una segunda faceta indicativa de la fuerza de este amor, es el hecho de que prevalezca sobre el amor filial que los padres tienen a sus hijos, y esta faceta se ilustra (235) con ejemplos tomados de la antigüedad clásica, y por tanto, del mundo pagano, con el caso de Catilina -que hizo asesinar a un hijo suyo ya crecido para obtener el amor de una mujer-, y el de Lenila -que provocó la muerte de sus hijos acusándolos ante el rey de traición para poder tener relaciones amorosas con un sirviente-. Esta segunda sección constituida por citas del ámbito pagano se cierra con la cita de Aristóteles que es objeto de nuestra atención: "Halatan erraiten du Aristotelek, ongi egin zutela lehenagoko poetek, Mars eta Venus elkharrekin ezkontzeaz: Mars gerla gizona eta Venus amurusiaren patroiña. Gerla eta amurusia ezkondu zituzten elkharrekin (Arist. lib. 2 Polit. cap. 1)"33. Axular cierra esta sección con una composición en anillo, es decir, repitiendo tras la argumentación la tesis que defendió al comienzo del capítulo.

Comenzamos por constatar que la cita es correcta en cuanto al libro en que aparece, que es el II, pero no en cuanto al capítulo (no es el 1, sino el 9). Por otro lado, lo que en la traducción del texto de Aristóteles que arriba presentamos está recogido como "el primer mitólogo", en una versión literal del griego sería "el que primero contó los mitos" (ho muthologésas prôtos), y tal personaje fue el poeta Homero, quien, efectivamente, en el canto VIII de la Odisea (versos 266-366) cuenta

también la ciudad debe considerarse dividida en dos partes aproximadamente iguales: el conjunto de los hombres y el de las mujeres; de suerte que en todos los regímenes en que va mal lo referente a las mujeres, hay que considerar que la mitad de la ciudad está como sin leyes. Es lo que precisamente sucede en Lacedemonia: el legislador, queriendo que toda la ciudad fuese resistente, se ve que lo logró en cuanto a los hombres, pero se ha descuidado con las mujeres, pues viven sin freno toda clase de intemperancia y molicie. Así, es forzoso en un régimen de tal tipo que la riqueza sea estimada, especialmente si los hombres son dominados por las mujeres, como la mayor parte de los pueblos militarizados y belicosos, excepto los celtas y algunos otros que estiman abiertamente el amor entre varones. Parece, en efecto, que el primer mitólogo, no sin razón, unió a Ares con Afrodita, pues todos los guerreros parecen inclinados al trato amoroso, ya al de los hombres, ya al de las mujeres. Por eso así sucedió entre los laconios ...". Política, II, 9, 1269.b.12-31; todas las traducciones de esta obra están tomadas de García Valdés, 1988; la edición griega es la de Ross, 1967 (reimpresión).

32 - "El amor desordenado ocasiona tantos daños que, una vez cegados, aun los que antes eran apacibles y pacíficos, los vuelve muchas veces, por el afán de cumplir sus deseos, traidores, duros de corazón, crueles y asesinos."

33 - "Por eso dice Aristóteles que bien hicieron los antiguos poetas casando a Marte con Venus (Arist. lib. 2 Polit. cap. 1). A Marte, hombre de guerra, y a Venus, patrona del amor carnal. Casaron entre sí a la guerra y al amor carnal. Porque comúnmente del amor carnal se originan las guerras y pendencias." 
cómo se unieron en amor Afrodita (Venus en latín), la esposa del dios Hefesto, y Ares (Marte en latín), el dios de la guerra, y cómo fue testigo de esta unión Helios, el dios sol, que corrió a contárselo a Hefesto. Este dios se vengó construyendo en su fragua una finísima red de hilos irrompibles en la que atrapó a los dos amantes y los expuso a la vista del resto de los inmortales. Lo cierto es que esta historia mítica que contaba Homero y a la que Aristóteles hace alusión, más que ilustrar los conflictos que surgen del amor desordenado (la vista de los dos amantes atrapados en la red sólo provocó la risa de los inmortales que los contemplaban), vendría a ser, en todo caso, un ejemplo más del amor que Axular llama "desordenado". Si Axular cita esta unión amorosa aquí puede deberse a que él mismo no conocía esta historia mítica o bien a que, conociéndola, suponía que era desconocida para sus lectores o para los receptores últimos de su obra. Dado que también cita determinados pasajes de Ovidio cuyo contexto encaja también poco con la moral que inspira el libro, hemos de inclinarnos por la primera posibilidad y admitir, con Salaberri ${ }^{34}$, que, si Axular realmente hubiera conocido el contexto en que las citas se encuentran en las obras originales, seguramente aparecerían de un modo más encubierto o directamente no aparecerían en él. La misma reflexión que acabamos de hacer sobre el contexto homérico, es válida para el aristotélico, ya que es poco probable que Axular lo hubiera citado en su obra, si hubiera sabido que la unión amorosa entre Ares y Afrodita no es más que un ejemplo de cómo los hombres belicosos suelen estar dominados por las mujeres, lo que les otorga a éstas un poder excesivo y constituye un punto débil en las constituciones. Teniendo en cuenta lo que Axular expresamente cita como aristotélico, comprobamos que seguramente sólo pudo disponer de una parte del último párrafo ("el primer mitólogo, no sin razón, unió a Ares con Afrodita") y que aun estas palabras podían estar a su vez modificadas, primero en la mención al primer poeta, que, al no ser identificable con facilidad, aparecía generalizado en el más vago "los antiguos poetas"; segundo, en el "unió a Ares con Afrodita", que, reconvertido a la moral al uso, dio el "casando a Marte con Venus" que aparece en Axular y permite poner este pasaje como ilustración de que el amor desordenado va unido a las guerras y pendencias. Parece claro a partir de estos datos que Axular desconocía no sólo el contexto mítico al que Aristóteles hacía referencia, sino también el contexto aristotélico, y que además estaba seguro de que todos los receptores de su obra lo desconocerían igualmente; efectivamente, entre esos receptores se encontraban sus censores, el Vicario General Perriquet, Salvatus de Dissaneche y el Doctor Theologus Petrus Durthubie, que otorgaron las Approbationes necesarias para que el libro saliera a la luz, en las que se aseguraba que no había en él nada en contra de la fe y la piedad ortodoxas y que su objetivo era conducir a las buenas costumbres.

El manejo que Axular hace de la cita aristotélica sugiere que o bien la tomó aisladamente de un listado de citas y que, sabiendo que Marte era dios de la guerra y Venus diosa del amor, su unión, convenientemente cristianizada, le pareció adecuada como ilustración de que guerra y amor suelen darse conjuntamente; o bien que esta cita se encontrara ya en otros textos como ilustración de esa unión; teniendo en cuenta que el propio Axular declara que sus fuentes son siempre de carácter religioso, lo más probable es que esta segunda opción sea la más cercana a lo realmente sucedido.

La Política aparece citada otras dos veces, en su libro V. Éste forma una unidad con el VI, ya que ambos tratan de las causas por las que las ciudades son prósperas o

34 - Salaberri, 1997, 291. 
pobres, como resultado de lo bien o mal administradas que estén bajo un mismo régimen político. En concreto, en el libro V estudia Aristóteles las causas de la inestabilidad de los regímenes políticos en los estados en general (1-4) y en los diferentes tipos de constitución en particular, la democracia, la oligarquía y la república (5-9). Al exponer las causas de la revolución y del mantenimiento de los regímenes monárquicos y tiránicos (10-11), entre los medios útiles para que la tiranía perdure se cita el siguiente:

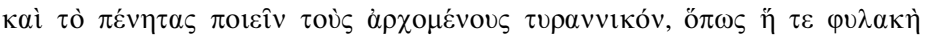

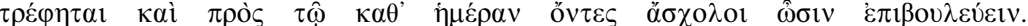

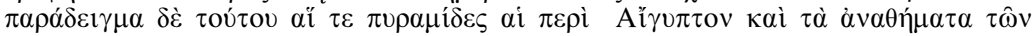

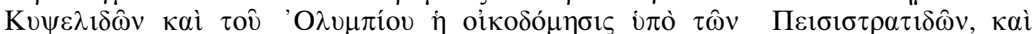

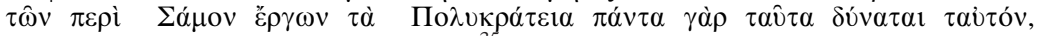

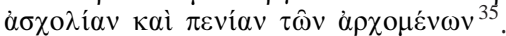

La cita correspondiente a este contexto aparece en capítulo 1, 15, p. 23. En este lugar se argumenta como sigue:

14. "Nola gure Iaungoikoak beztitu baitzituen lurreko animaliak, aireko hegaztinak, itsasoko arraiñak, eta ohianeko zuhaitzak ere, bere beztimenda suerte batzuez. Animaliak larruz eta illez: hegaztinak lumaz: arraiñak ezkataz: eta zuhaitzak azalez.

Eta nola zuhaitzak bere dauden lekhuetarik higitu gabe, eta trabaillatu ere gabe, bere azpiko lurraren gozoa eta gizentasuna, beregana, bere erroez thiratuz eta edoskiz, hazten, handitzen eta mantenatzen baitira: animaliek ere bere bazkak eta iatekoak, berehala, eho gabe, erre eta egosi gabe, iaten baitituzte: eta bai bere etxeak eta etzauntzak ere, non nahi den, arratsten eta ilhuntzen zaien lekhuan hartzen: eta gehienak, berehala bere ameen ondotik baitoazi; zein baitira abantail handiak. Hala Iainkoak nahi izan balu, eman zerauzkaion gizonari ere abantail suerte hauk guztiok, eta gehiago ere. Beztitu zukeien, etxedun egin zukeien. Ordea etzuen hala ibeni nahi izatu. Eta zergatik ez? Alfer etzegoen amoreakgatik. Eta San Anbrosiok dioen bezala, errezibitu duen adimendua enplega dezangatik. Soli autem bomini, ut rationale quod accepit exerceat, vitae cursus in labore praescribitur (Ambros. in praefat. in Levit). Zeren baldin orai, gauza guztiak hain nekez eta hanbat gostarik, erdiesten ditugularik, hain nagi eta alter bagara; zer geneidike, nahi dugun guztia, nahi bezala eskuen artean bagendu? Deus falta ezpalitzaiku? Erran genezake Ebanjelioko aberats hark bezala: Anima, habes multa bona, posita in annos

35 - "También hacer pobre a sus súbditos es una medida tiránica para que no sostengan una guardia y, ocupados en sus trabajos cotidianos, no puedan conspirar. Un ejemplo de esto son las pirámides de Egipto, las ofrendas votivas de los Cipsélidas, la construcción del templo de Zeus Olímpico por los Pisistrátidas, y entre las obras de Samos, las de Polícrates (pues todas estas empresas producen el mismo efecto: ocupación y pobreza de los súbditos)." Política V, 11, 1313.b.18-25. Esta traducción de García Valdés se basa en noticias (Platón, República VIII 567.a-e, Diodoro, XI, 67.5 y la propia Política V, 10-11, 1311.a.14) que mencionan una guardia cívica (además de la de mercenarios del tirano) que mantendría el pueblo y que solía ser desprovista de sus armas por los tiranos; cf. García Valdés, 347, n. 1197. La misma estudiosa apunta también que puede referirse aquí a las altas contribuciones que se imponían a los ciudadanos para pagar la guardia mercenaria de la que se rodeaban los tiranos. 
plurimos, requiesce, comede, bibe, epulare (Lc. 12). Dezagun ian eta edan; dezagun pausa eta atsegin har; zeren berdin eztugu deusen eskasik, eztugu egun hautan eskean ibiltzeko perilik.

15. Erraiten du Aristotelek, on dela, alferkeriaren herritik khentzeko, eta desterratzeko: eta herrien ere bere erregeren edo bertzeren kontra iaikitzetik begiratzeko, zenbait obra handiren hastea, zenbait dorreren edo gazteluren egitea, eta hetan iendearen enplegatzea (Arist. lib. 5 Politic. cap. 11). Nola ageri baita Ejiptoko Piramidetan, zein eragin baitzituen errege Faraonek, iendeak alfer etzeudezin amoreakgatik." 36

La tesis que Axular defiende aquí es que Dios no quiso que el ser humano estuviera ocioso y lo prueba exponiendo, primero, que si así lo hubiera querido, le habría provisto de todo lo necesario sin tener que hacer ningún esfuerzo, como sucede con los animales y las plantas. Esta idea se refuerza con otras dos sacadas de textos religiosos, una de San Ambrosio, que insiste en que sólo el ser humano debe trabajar, ejercitando para ello su inteligencia, y otra sacada del Evangelio ${ }^{37}$, en la que se ilustra el grado extremo de molicie al que llegaría si todo lo tuviera a su alcance con facilidad. La argumentación se cierra con la cita aristotélica, que es correcta en el libro (V) y capítulo (11) que se da. La adaptación que esta vez aparece en Axular es mucho más respetuosa con el contexto original: se suprime la idea de empobrecer al pueblo, que no era pertinente a la tesis de Axular, pero, al hilo de evitar la holgazanería, se conserva la de mantenerlo ocupado para evitar que se levante, no ya contra un tirano, figura política desconocida en época de Axular, sino contra el rey, conservándose de este modo el contexto político general de Aristóteles. De las grandes construcciones que el estagirita menciona, se mantiene sólo la mención de las pirámides de Egipto, sobre las cuales Axular explica en las líneas que siguen al pasaje citado qué son, cómo son y cómo fueron construidas, de manera que en absoluto presupone que el destinatario de su obra pudiera tener datos sobre ellas. El resto de las construcciones que aparecen en Aristóteles se recogen en la mención de las torres y los anacrónicos castillos, que sugieren que también esta cita podía haberse tomado ya adaptada a los tiempos de Axular de alguna otra obra.

36 - "Así como nuestro Dios vistió a los animales terrestres, a las aves del cielo, a los peces del mar y a los árboles de la selva con su vestimenta peculiar; a los animales de piel y pelos; a las aves, de plumas; a los peces, con escamas; y a los árboles, de corteza. Y así como los árboles, sin menearse del lugar donde se encuentran, y sin trabajar, se mantienen, alimentan y crecen, chupando y aspirando hacia sí con sus raíces el jugo y la grosura de la tierra que está debajo de ellos; y los animales, asimismo, comen sus alimentos inmediatamente, sin molerlos, asarlos ni cocerlos; y en cuanto a casa y cama, en cualquier lugar en que les anochece y oscurece, allí se la procuran; y la mayor parte de ellos luego al punto saben ir en pos de sus madres: todas las cuales son grandes ventajas. Así también, si Dios hubiera querido, podía haberle dado al hombre todas estas ventajas, y aun mayores. Podía haberle vestido, haberle dado casa, y haberle hecho poseedor de cuanto necesita sin costarle nada. ¿Y por qué no lo hizo? A fin de que no estuviera ocioso. Y, como dice San Ambrosio, a fin de que ejercite el entendimiento que ha recibido. "Soli autem homini, ut rationale quod accepit exerceat, vitae cursus in labore praescribitur" (Ambros. in praefat. in Levit.). Porque si ahora, que conseguimos las cosas con tanta dificultad y costándonos tanto, somos tan perezosos y vagos, ¿qué sería si tuviéramos entre las manos todo cuanto queremos? ¿si nada nos faltara? Podríamos decir como aquel rico del Evangelio: "Anima, habes multa bona posita in annos plurimos, requiesce, comede, bibe, epulare" (Lc. 12). Comamos y bebamos, descansemos y gocemos, porque al fin y al cabo no nos falta nada ni hay miedo de tener que ir a pordiosear. 15. Dice Aristóteles (Aristóteles. lib. 5 Politic. c. 11) que es bueno, para desterrar y suprimir del Estado la holgazanería, y para preservar a los pueblos de levantarse contra su rey o contra otros, el emprender algunas obras grandiosas, el construir ciertas torres o castillos y ocupar en ello a la gente. Como se ve en las Pirámides de Egipto, las cuales hizo construir el rey Faraón, con el fin de que el pueblo no estuviera ocioso." 37 -Salaberri, 1997, 300-301, constata que las citas y los ejemplos que aparecen en Axular están tomados en grupos, donde se acumulan citas varias relativas al mismo tema. 
La segunda cita que en el Después se atribuye al libro V de la Política, por cierto que sin indicar el capítulo, pertenece en realidad al libro VI, capítulo 4. En este libro se analizan los modos de organización y de conservación de la democracia (1-5), y al estudiar los tipos de ésta podemos leer:

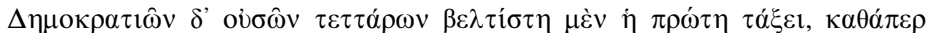

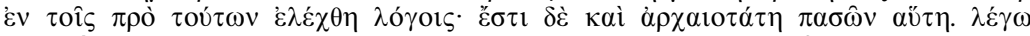

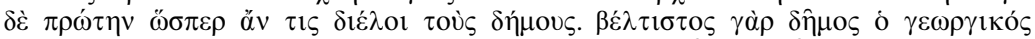

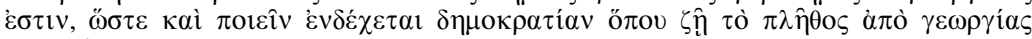

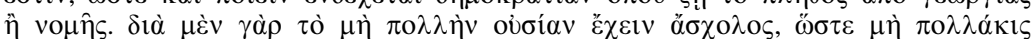

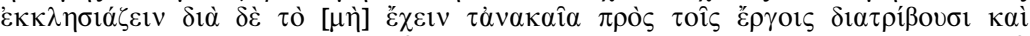

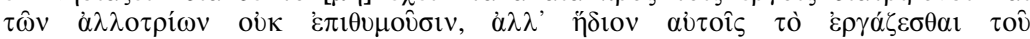

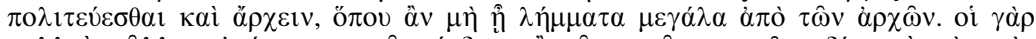

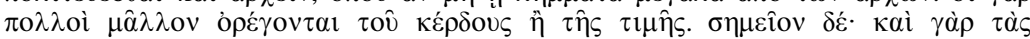

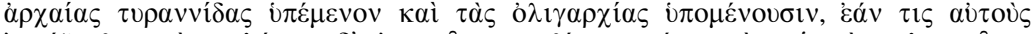

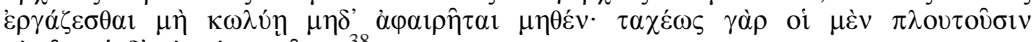

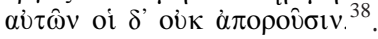

Este contexto aristotélico aparece mencionado en el capítulo 38, 249, p. 425:

249 "Trabailla zaite, egitekotan ibil zaite, zerbaitetan enplega zaite, alfer egoitetik begira zaite, eta halatan begiratuko zara emaztèkin huts egitetik ere. Zeren alferkeriatik heldu da amurusia, emaztètako gogoa, orhoitzapena. Eta bai malizia pensatzea, eta nahastekamenduen egitea ere. Halatan erraiten du Aristotelek: Nekhazalerik, eta laboraririk baizen ezten herria, dela herririk hoberena (Arist. lib. 5 Politic.).

Zeren nekhazaleak bere nekeaz eta trabailluaz baitaduka kontu, eta ez amuruziaz, eta ez nehoren nahastekatzèaz"39.

En este caso es notoria también la ausencia del contexto aristotélico, que es de nuevo un contexto político: los campesinos son el pueblo mejor para mantener una democracia, en tanto que su escasa fortuna les obliga a trabajar mucho y no pueden participar, por tanto, en las instituciones democráticas, o en tanto que, más atentos a obtener ganancias que honores, prefieren trabajar, porque les es más rentable que recibir la exigua compensación económica que en tiempos de Aristóteles la ciudadestado pagaba a los ciudadanos que acudían a la asamblea, es decir, en definitiva, en

38 - "Siendo cuatro las democracias, la mejor es la primera de la serie, como se dijo en las consideraciones precedentes, y ésta es también la más antigua de todas. Yo la llamo primera en el mismo sentido en que se pueden clasificar los pueblos: el mejor pueblo es el campesino, de modo que es posible establecer también una democracia donde la muchedumbre vive de la agricultura o de la ganadería. En efecto, por no tener mucha fortuna está tan ocupado que no puede asistir con frecuencia a la asamblea; y por no tener las cosas necesarias, pasan el tiempo en sus trabajos y no desean lo ajeno, sino les es más grato trabajar que dedicarse a la política y ejercer el mando, cuando las ganancias que sacan de los cargos no son grandes; pues la mayoría aspira más al lucro que al honor. Una prueba de ello es que soportaban las antiguas tiranías y soportan las oligarquías, si no se les impide trabajar, ni se les quita nada; pues los unos se enriquecen rápidamente, y los otros no están en la indigencia." Política VI, 4, 1318.b.6-21.

39 - "Trabaja, ocúpate en quehaceres, empléate en algo, guárdate de estar ocioso, y así te guardarás también de faltar con las mujeres. Porque de la ociosidad se origina el enamorarse, el pensamiento y recuerdo de mujeres. Y también el maquinar maldades y provocar revueltas. Así lo dice Aristóteles: el pueblo mejor es aquel donde no hay más que labradores (Arist. lib. 5 Politic.). Y es que el labrador bastante tiene con pensar en su fatiga y trabajo, sin acordarse de enamoramientos ni de revolver a nadie. Al que trabaja o se ocupa en quehaceres, la carne no le tienta mucho. Al contrario, sus trabajos, aflicciones y quehaceres ya le dan bastante en qué ocuparse." 
tanto que, ocupados en sus trabajos, no interfieren o se ocupan en la gestión política. Esta idea, la central de Aristóteles, sólo de soslayo se menciona en Axular ("Eta bai malizia pensatzea, eta nahastekamenduen egitea ere...", “... eta ez nehoren nahastekatzeaz."), y es la que puede haber llevado a citar este pasaje como perteneciente al libro V, porque también allí se hacía alusión a la importancia de mantener al pueblo ocupado. Aquí, en cambio, se utiliza para ilustrar otro aspecto pecaminoso que conlleva, según Axular, la ociosidad, como es el trato pecaminoso con mujeres. Una vez más, parece bastante probable que esta asociación entre el trabajo duro (como el de los campesinos) y la evitación de los pecados de la carne hubiera sido ya realizada en medios religiosos antes que lo hiciera Axular.

La Ética aristotélica se encuentra citada en el Capítulo 7, 62, p. 99 de Axular. El contexto en el que esta cita aparece es el siguiente:

59 (Comienzo del capítulo 7) "Erraiten du Spiritu Sainduak: Adolescens iuxta viam suam, etiam cum senuerit non recedet ab ea (Prov. 22). Nor nola gobernatzen baita gaztean, hala komunzki egiten ohi da, zahartzean ere. Orduan hartzen duen bidea, plegua, eta usantza, edukitzen du gerorat ere: ezta handik aldaratzen, hari itxetkitzen zaika... 60 (Comienzo) Denbora luzeaz bekhatutan egoiteaz eta usatzeaz, bertze kalterik ethor ezpaledi ere, pleguaren eta aztura gaixtoaren hartzea baizen ere, hura bera behar lizateke asko, bekhatutan pausatzetik begiratzeko, eta lehen baiño lehen bide onean iben arazitzeko. Zeren hain du indar handia usantzak, ezen erraiten baitu San Krisostomok... 61 (Final) Bekhatuaren usantzak gaitzten du berthutearen bidea: ordea baldin usantza hura itzul badadi bertze aldera, gaixtatasunetik ontasunera, edirenen da berthutearen bide hura bera, errax, atsegin, eta plazent. Eskiribatzen hasten zarenean, ezin higi ditzakezu erhiak, lothuak bezala daude. Zeren ezpaitira usatuak. Baiña gero eta gero usatzen eta trebatzen dira, hain trebatzen, ezen azkenean, bertze alderat beha zaudela ere, hitzen erdiak eskiribatzen baititutzu. Hala ikhusiko duzu dendari baten etxean ere, ofizialeak abiadura handia daramala, pontuak husu eta laster emaiten tuela; baiña aprendiza bakhan, barath, eta pontuak kontatuz bezala hari dela. Zeren ezpaita aprendiza ofizialea bezala usatua, ohitua eta trebatua.

62 (Comienzo) Halatan erraiten du Aristotelek: Ex actu multoties iterato fit habitus (Arist. lib. 2 Ethic.). Ez behingoaz, baiña maiz eta anhitzetan usatzeaz egiten da trebetasuna, eta aztura"40.

La frase tal como se cita no aparece ni en la Ética a Nicómaco ni en la Ética a Eudemo de Aristóteles, si bien en el libro II de ambas aparece la idea que Axular está defendiendo y quiere apoyar con la autoridad del estagirita. En la Ética a Eudemo podemos leer:

40 -"Dice el Espíritu Santo (Prov. 22): "Adolescens iuxta viam suam, etiam cum senuerit non recedet ab ea". Según como se comporta uno de joven comúnmente lo hace de la misma manera cuando es viejo. El camino, costumbre y hábito que entonces toma, lo retiene también en lo sucesivo: no se mueve de él, no se aparta de él, a él se adhiere... 60. Aun suponiendo que de permanecer largo tiempo en el pecado no se siguiera otro daño que el de adquirir la inclinación y el mal hábito, ello sólo debería bastar para guardarse de detenerse en él y para ponernos cuanto antes en el buen camino. Porque la costumbre tiene una fuerza tan grande, que dice San Crisóstomo ..." 61. (final) "La costumbre del pecado dificulta 


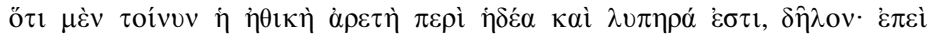
$\delta^{\prime} \varepsilon \sigma \tau \grave{\imath}$ ¿̀̀ $\hat{\eta} \theta$ os,

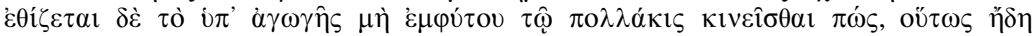

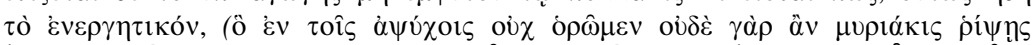

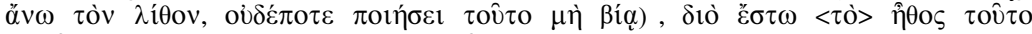

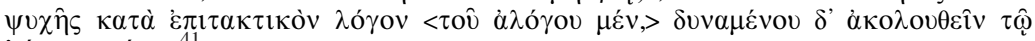
$\lambda$

Para entender en su pleno sentido este pasaje, hay que apuntar que "virtud ética" se dice en griego ethikè areté, y que ethiké, "ética", es un adjetivo derivado de êthos, "carácter"; esta misma forma, pero con una e breve, éthos, es en griego el "hábito", de manera que "hábito", "carácter" y "ético" son en griego antiguo palabras que tienen una misma raíz ${ }^{42}$. Se desprende de este pasaje que la virtud ética (etbiké) o del carácter (êthos) se adquiere gracias al hábito (éthos), que, a su vez, resulta de la repetición de los mismos actos muchas veces, tal como aparece en la cita latina de Axular. Esta misma idea se encuentra también en la Ética a Nicómaco:

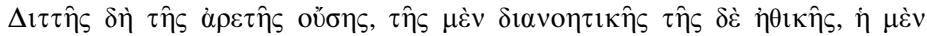

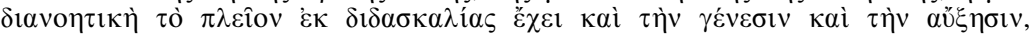

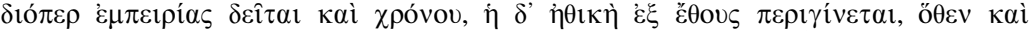

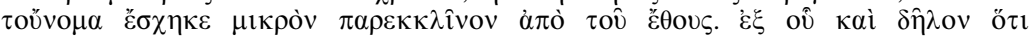

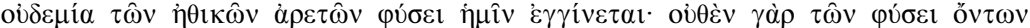

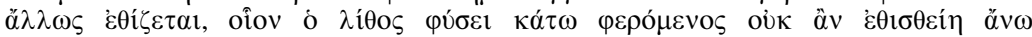

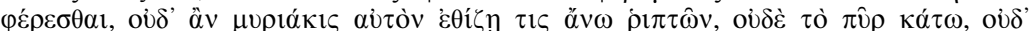

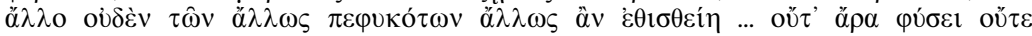

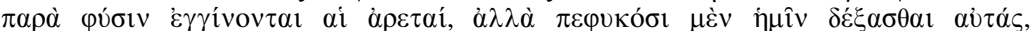

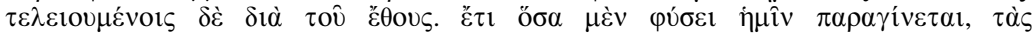

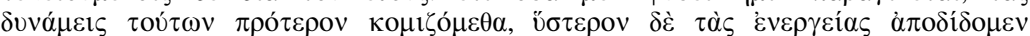

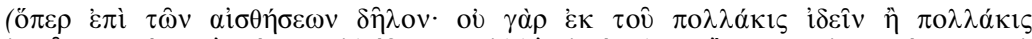

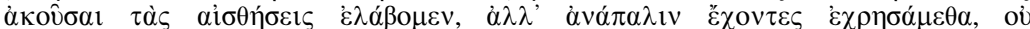

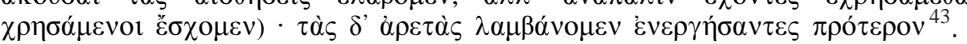

La idea aristotélica de que el hábito se produce por la repetición está enmarcada en un contexto muy concreto, el de la virtud ética, la cual se logra repitiendo acciones y por la especial cualidad del alma humana, que tiene la capacidad innata de adquirir esa virtud, gracias a la repetición de determinados actos. De nuevo el marco aristotélico ha desaparecido de la cita de Axular y lo que en éste se conserva de aquél es una frase, que se ofrece como una cita literal de palabras de Aristóteles

el camino de la virtud: mas si la tal costumbre se torna al otro lado, de la maldad al bien, entonces este mismo camino de la virtud resultará fácil, agradable y placentero. Cuando empiezas a escribir, no puedes poner los dedos, están como atados. Es que no están acostumbrados. Pero luego se van acostumbrando y adiestrando más y más; y de tal modo se adiestran, que, al fin, aun estando mirando al otro lado, escribes la mitad de las palabras. Así verás también que en la casa del sastre el oficial trabaja con gran rapidez y hace muchos puntos y velozmente; pero el aprendiz hace pocos, lentamente, y anda como contándolos. Y es porque el aprendiz no está tan acostumbrado, habituado y adiestrado como el oficial. 62. Por eso dice Aristóteles: "Ex actu multoties iterato fit habitus" (Arist. lib. 2 Ethic.). No por una vez, sino repitiendo con frecuencia y muchas veces es como se adquiere la soltura y la costumbre."

41 - "Es evidente, pues, que la virtud ética está en relación con lo agradable y lo penoso. Y, puesto que el carácter, como lo indica su nombre, recibe su crecimiento del hábito, gracias a numerosos movimientos de un cierto tipo, un hábito no innato en nosotros resulta, finalmente, educado para obrar en un sentido (cosa que no vemos en los seres irracionales, pues aun cuando lances hacia arriba una piedra diez mil veces, jamás subirá, sino por fuerza). Sea, pues, el carácter una cualidad de la parte irracional del alma, capaz, según la razón imperativa, de obedecer a la razón." Ética a Eudemo, 1220.a.381220.b.6 Edición de F. Susemihl, 1967. La traducción de la dos Éticas está tomada de Julio Pallí Bonet, 1988.

42 - Sobre el significado originario de êthos y su evolución, cf. E. Redondo Moyano, 2006, 25. 
pero que, en realidad, es la expresión de una de las ideas que en él aparecen, la de que el hábito se forma por la repetición de acciones, hecho, por cierto, que es una verdad general, algo por todos conocido pero que resultaba, al ser atribuido a Aristóteles, revestido con la autoridad que de él emanaba.

El Sobre el alma aristotélico se encuentra citado en el capítulo 9, 78, p. 129. La argumentación que aquí se desarrolla se inicia con la siguiente idea:

74 (Comienzo del capítulo 9): "Erraiten du Salomonek, Iainkoarekin mintzo dela: Omnia in mensura et numero et pondere disposuisti (Sap. 11). Iauna, zure gobernua eta ordenamendua, hain da handia, eta hain aitzina heltzen eta hedatzen da, non munduko gauza guztiak kontuan, pisuan eta neurrian egiten baitituzu." Esta idea se desarrolla en 75, 76 y 77 de los que reproducimos aquí sólo las ideas iniciales, que sirven para seguir el hilo argumentativo: 75 "Ordea guztiarekin ere badaki Iainkoak gure bekhatu guztien berria eta kontua..." 76 "Bada itsasoari bezala ibeni derauka Iainkoak gizonari ere, bere arauaz bere sedaría, seiñalatu dio noreraiño hel, bere xedea, bere mugarria eta marra." 77 "Itsasoko untziak, barkha handiak, anhitz daduka, karga handia iasaiten du. Erditaraiño betheagatik, itsas gaiñean dago. Hirur laurdenak betheagatik ere badabilla, oraiño ageri da. Guztia betha dadinean, hondatzen, eta ondoratzen da, orduan estaltzen da. Zeren ezta, soberaniak gaiñez eragin eztiazaionik, ezta bere neurria baiño gehiago dadukaionik. Bada haur beror gerthatzen zaitzu, zeure bekhatuen kargarekin, zuri ere." Esta idea de que todo tiene una medida determinada de la que no se puede pasar, es la que aparece confirmada por la cita aristotélica con que se inicia el capítulo 78 "Erraiten du Aristotelek eta hari iarraikitzen zaitza bertze filosofo guztiak ere: Omnia viventia quae dicuntur natura constantia, babent certum limitem suae quantitatis (Arist. 2 ex anima cap. 4 text. 41). Bizitzen diren gauza guztiek, badute bere neurria bere handitasunean, eta bai ttipitasunean ere... Ordea guztiek dute bere denbora iakin bat, eta neurri bat. Hala dute bada bekhatuek, eta bekhatoreek ere bere arauaz bere neurria eta kontua zenbatetaraiño hel, eta bai denbora ere noizarteraiño iraun. Eta denbora hura konplituz gero, neurria bethez gero, eztu Iainkoak gehiago igurikitzen." ${ }^{44}$

En la referencia que se menciona en Después, el libro II, capítulo 4 de Sobre el alma, Aristóteles se ocupa de analizar la facultad nutritiva del alma, entidad que, en opinión suya, existe en todos los seres vivientes, ya que en virtud suya se da el vivir, y obras suyas son el engendrar y el alimentarse. Pero, como es habitual en el estagirita, en su análisis expone también las teorías de otros al respecto:

43 - "Existen, pues, dos clases de virtud, la dianoética y la ética. La dianoética se origina y crece principalmente por la enseñanza, y por ello requiere experiencia y tiempo; la ética, en cambio, procede de la costumbre, como lo indica el nombre que varía ligeramente del de "costumbre". De este hecho resulta claro que ninguna de las virtudes éticas se produce en nosotros por naturaleza, puesto que ninguna cosa que existe por naturaleza se modifica por la costumbre ... De ahí que las virtudes no se produzcan ni por naturaleza ni contra naturaleza, sino que nuestro natural puede recibirlas y perfeccionarlas mediante la costumbre. Además, de todas las disposiciones naturales, adquirimos primero la capacidad y luego ejercemos las actividades. (Esto es evidente en el caso de los sentidos; pues no por ver muchas veces u oír muchas veces adquirimos los sentidos, sino al revés: los usamos porque los tenemos, no los tenemos por haberlos usado.) En cambio adquirimos las virtudes como resultado de actividades anteriores." Ética a Nicómaco, II, 1, 1103.a.14-32, la edición de I. Bywater, 1894 (reimpresión de 1962). 


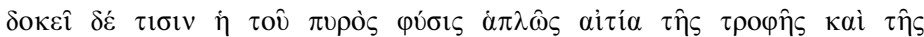

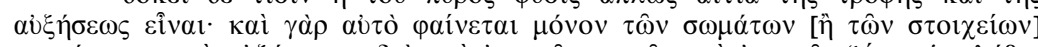

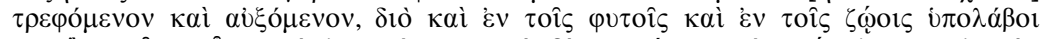

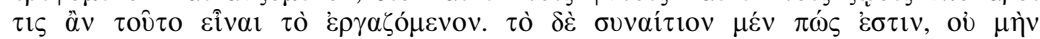

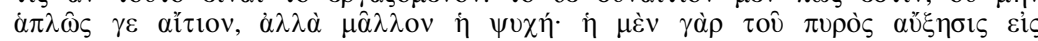

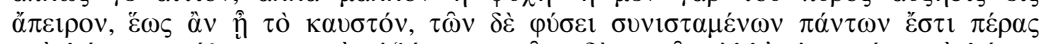

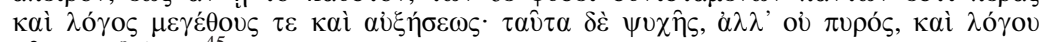

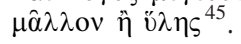

Aunque de nuevo la cita latina parece hacer referencia a unas palabras literales de la obra de Aristóteles, nos encontramos aquí, como en el caso de la Ética, que lo que en ellas se recoge es una idea contenida en la argumentación aristotélica. Y de nuevo también esta idea ha quedado reducida a una verdad de conocimiento general, que aparece en el texto de Axular refrendada primero por una autoridad religiosa (Salomón), y luego por la cita aristotélica, de modo que puede hacerse extensiva no sólo a Aristóteles, sino a todos los filósofos, para ser aplicada a un contexto radicalmente distinto, la idea de que el número de pecados que se pueden cometer es tan limitado como la vida humana.

\section{La cita de la Física}

En relación con el tiempo se cita también la cuarta obra aristotélica, la Física, en el capítulo 12, 102, p. 171. Hemos separado esta cita de las demás porque su

44 - 74 "Dice Salomón hablando con Dios: "Omnia in mensura et numero et pondere disposuisti" (Sap. 11.). Señor, tu gobierno y tu ordenación de tal modo es grande y se extiende y alcanza tan lejos, que todas las cosas del mundo las haces en número, peso y medida." 75 "Con todo, Dios sabe y numera todos nuestros pecados: sabe cuántos cometeremos y sabe también hasta dónde nos esperará." 76 "Pues lo mismo que al mar, le ha puesto Dios también al hombre un límite según su medida, le ha señalado hasta dónde ha de llegar, su tope, su mojón, su raya." 77 "El navío de mar, el barco grande, cabe mucho, soporta una carga grande. Aunque se le llene hasta la mitad, se mantiene sobre el mar. E incluso con las tres cuartas partes llenas, aún todavía marcha y todavía se le divisa. Cuando se llena totalmente, se hunde y se va a pique, entonces desaparece. Porque no hay cosa a la que la demasía no la haga desbordar, ni que pueda contener más que su capacidad. Puesto esto mismo es lo que te sucede a ti también con la carga de tus pecados." 78 "Dice Aristóteles y a él le siguen todos los demás filósofos: "Omnia viventia quae dicuntur natura constantia, habent certum limitem suae quantitatis" (Arist. 2 ex anima cap. 4 text. 41). Todas las cosas que viven tienen su medida en su magnitud y también en su pequeñez ... Mas todos tienen un tiempo prefijado, y una medida. De esta manera tienen los pecados y también los pecadores su medida y número hasta cuánto llegar, y también su tiempo, hasta cuándo vivir. Y una vez cumplido dicho tiempo y llenada la medida, Dios no aguarda más."

45 -"Otros opinan que la naturaleza del fuego es, sin más, la causa de la nutrición y del crecimiento puesto que, a lo que se observa, es el único entre todos los cuerpos o elementos que se nutre y crece. De ahí que alguien pueda opinar que también es él el que realiza tal función en las plantas y animales. Sin embargo, es en cierto sentido concausa, pero no causa sin más: ésta es más bien el alma. Pues el crecimiento del fuego no tiene límite, en tanto dura el combustible, mientras que todos los seres naturalmente constituidos tienen un límite y una proporción en cuanto a su tamaño y crecimiento. Ahora bien, esta configuración corresponde al alma y no al fuego, a la forma más bien que a la materia." Sobre el alma, 416.a.9-18: Edición de W. D. Ross (ed.), 1961 (reimpresión de 1967); la traducción está tomada de Calvo Martínez, 1978. Que los seres vivos tienen medida aparece también un poco más adelante (416.b.11-17), cuando se trata de los alimentos: ̌̋

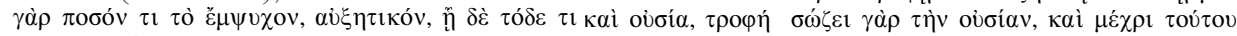

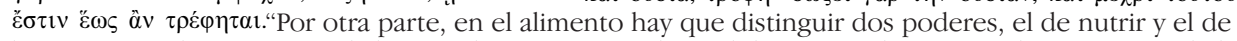
hacer crecer: de una parte, el alimento hace crecer, en la medida en que el ser animado posee cantidad, y de otra, alimenta en la medida en que es individuo y entidad: el alimento, en efecto, conserva la entidad y ésta pervive gracias a él en la medida en que se alimenta." 
función es diferente. En el facsímil de Después se observa también una diferencia en la forma de aparecer en la obra, ya que el texto latino, como arriba hemos comentado, se cita en el margen y no en el cuerpo del escrito. Esta cita aparece en un contexto en el que Axular expone que no debe aplazarse nada para después porque el único tiempo del que el ser humano dispone es el presente. Esta argumentación se elabora así:

101. "Gerotik gerora zabiltza; urthe hunetan gaixto izanik, dathorkeienean onduko, eta prestutuko zarela diozu. Bada biz hala, zuk diozun bezala, eta gogoan darabillazun bezala, gertha dakizun, eta urthe hunetan gaixto, izanik, zure gero horretan, ethorkizunean prestu zaitezin. Hori horrela baliz ere, non da bataz, urthe hunetan egin ahal zendukeien irabazia eta aitzinamendua? Zeren giristino onek, urthe batez anhitz obra on egiten dute, eta bai meritu ere erdiesten: giristino onak urthe batez, aitzinatzen dira, baiña zu nola aitzinatuko zaren ezen gibelatzen zara, anhitz bekhatu eta gaixtakeria egiten duzula. Eta berriz bertzea, non da halaber bitartean, urthe hunetan zure Gero horretara hel arterainokoan galtzen duzun denbora? Fili, conserva tempus (Eccli. 4). Ene seme, begira ezazu denbora, dio Espiritu Sainduak. Aitzinean duzuiño, zakitza. Zeren behin oianez gero, ezta bihurtzerik, eta ez erdiesterik.

Fronte capillata est, et post occasio calva (Auson.). Okhasinoa kopetan, belarrean, aitzin aldean, illetsu da, eta xerlotsu, baiña garhaitean, garzetan, gibel aldean, motz, soil, garbal, karsoil, eta ille gabe. Aitzinean badu nondik lot, baiña ez gibelean. Beraz, aitzinean duzuiño, probetxa zakitza. Zeren gibeleraz gero, eztu esku-tokirik, eta ez lotzeko girthainik. Bada okhasinoa bezala da denbora ere. Beraz hunelatan: Quodcumque potest facere manus tua instanter operare. Quia nec opus, nec ratio, nec sapientia, erit apud inferos quo tu properas (Eccl. 9). Orai, denbora aitzinean duzuiño, egizu ahal dagizuna: eta orai ere, Instanter, fite, presenteon. Zeren iakin behar duzu ezen eztela gero, zuk ioan behar duzun lekhu hartan, arrazoin alegatzerik, eta ez iakintasunaz probetxatzerik izanen. Utzten baduzu, nola eztakizula, orai eskuen artean duzun denbora iragaitera, egin da, galdu da, ezta gehiago bihurtzerik. Hargatik erraiten du Iondone Paulok: Dum tempus habemus, operemur bonum (Gal. 6). Denbora duguiño dagigun ongi.

102. Erran beza Aristotelek nahi duena denboraz (Tempus est numerus motus, secundum prius et posterius ${ }^{, 46}$ (Aristot., 4 Physic.). Baiña gure kontuko, denbora da lehen, orai eta gero, gauzeen ibiltzea, iragaitea eta iragaitearekin batean higatzea eta akhabatzea. Denbora bethi doha. Neque quod futurum est meum, neque quod fuit, dio Senekak (Senec. lib. Natur. quaest.). Iragana, eta ethorkizuna eztira gure. Ioana ioan, ethorkizuna ethorkizun, presentekoa da gure, eta ez bertzerik"47.

46 - "El tiempo es número en movimiento, según el pasado y el futuro."

47 - 101. "Andas aplazando indefinidamente, dices que serás malo este año, pero que te enmendarás y convertirás en el que viene. Pues sea así, como tú dices, y que te suceda como proyectas, y que siendo malo este año te hagas bueno en ese futuro o mañana. Mas aun suponiendo que así ocurriese, ¿dónde está por un lado el mérito y adelantamiento que en ese año podías haber ganado? Porque los buenos cristianos en un año practican muchas obras buenas y asimismo ganan muchos méritos: los buenos cristianos en un año adelantan, pero tú ¿cómo vas a adelantar si vas para atrás cometiendo muchos pecados y maldades? Y por otro lado, ¿qué se hace del tiempo que durante este año pierdes, hasta llegar a ese tu "Después?" "Fili, conserva tempus" (Eccli 4) Hijo mío, cuida del tiempo, dice el Espíritu Santo. Mientras lo tienes ante tí, aprovéchalo. Porque una vez pasado, no hay posibilidad de volverlo ni de alcanzarlo. "Fronte capillata est, et post occasio calva" (Auson.) La ocasión en la frente, por la parte delantera, es peluda y cabelluda, pero en la cerviz, en la nuca, en la parte posterior, es mocha, pelada, 
La función de esta cita no es, como en los casos anteriores, confirmar algo que se expone, sino que, por el contrario, se menciona a Aristóteles para negarle credibilidad. En el contexto de la Física que apunta Axular encontramos lo siguiente:

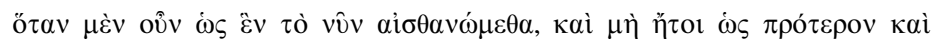

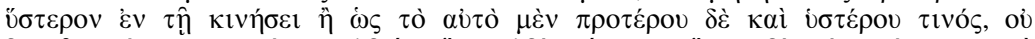

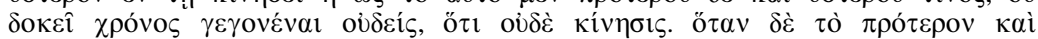

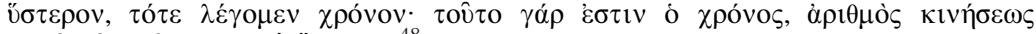

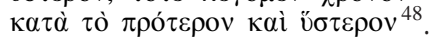

Según la teoría aristotélica el tiempo, en tanto que es un movimiento que no cesa, pasa continuamente de ser un "antes" a ser un "después". Esto implicaba que el presente no existía, y esta idea está en clara contradicción con la que a Axular le interesaba defender, que el presente es el único tiempo del que el ser humano dispone para obrar bien. Esta idea aparece reflejada a lo largo de todo el pasaje de Axular y se ve confirmada con citas de diversos textos sagrados, además de otras dos de gentiles, la de Ausonio, que precede a la de Aristóteles y la de Séneca, que viene después. Es la de Aristóteles, por tanto, la única que aparece contradiciendo o sin encajar bien con lo que Axular quería demostrar. Es inevitable preguntarse, entonces, por qué aparece. En primer lugar, es muy posible que lo hiciera porque su teoría del tiempo fuera lo suficientemente conocida en los ambientes culturales en los que Axular y los lectores de su libro se movían como para que pudiera dejar de mencionarla. Efectivamente, esta cita se encuentra en una colección de sentencias filosóficas conocida como Parui flores o Auctoritates Aristotelis ${ }^{49}$, colección que fue la más difundida entre los siglos XIII y XVII, durante los cuales fue utilizada como libro de texto en las facultades de arte de muchas universidades, facultades estas a las que era obligatorio que acudieran todos aquellos que quisieran cursar derecho, teología y otros estudios ${ }^{50}$. Y no podemos olvidar que Axular, que

calva y sin pelo. Por delante ya tiene por dónde cogerla, pero por detrás no. Por lo tanto, mientras la tienes delante, aprovéchala. Porque una vez vuelta al lado posterior, no tiene dónde echar la mano, ni asidero para cogerla. Pues bien, con el tiempo ocurre lo mismo que con la ocasión. Siendo esto así: "Quodeumque potest facere manus tua instanter operare. Quia nec opus, nec ratio, nec sapientia erit apud inferos quo tu properas" (Eccl. 9). Ahora, mientras el tiempo lo tienes delante, haz lo que puedas: y aún ahora, "Instanter", rápidamente, inmediatamente. Porque has de saber que en aquel lugar al que tienes que ir, no valdrá luego alegar razones ni aprovechará el saber. Si dejas pasar, sin reparar en ello, el tiempo que ahora tienes entre manos, se acabó, aquello se perdió, no vuelve más. Por eso dice San Pablo: "Dum tempus habemus, operemur bonum" (Gal. 6). Mientras tenemos tiempo, obremos bien. 102. Diga Aristóteles lo que quiera acerca del tiempo: "Tempus est numerus motus, secundum prius et posterius" (Aristot., 4 Physic.). Pero para nuestra cuenta, el tiempo es un caminar de las cosas antes, ahora y después, un pasar, y a la medida que pasan, un gastarse y acabarse. El tiempo siempre camina. "Neque quod futurum est meum, neque quod fuit", dice Séneca (Senec. Lib. Natur. Quaest.). El pasado y el futuro no son nuestros. El pasado se fue, el futuro está por venir, el presente únicamente es nuestro."

48 - "Ahora bien, cuando percibimos el ahora como uno, y no como "antes" y "después" en el \{proceso del $\}$ movimiento, y no como lo mismo, sino como \{separado $\}$ en algo anterior y posterior, entonces no parece haber pasado ningún tiempo, porque tampoco hubo movimiento. Pero cuando \{percibimos\} el "antes" y "después", entonces lo llamamos "tiempo", pues éste es el tiempo: el número en movimiento en relación a lo "antes" y "después". Física, 219.a.30-219.b2, la edición es la de D. Ross (ed.), 1950 (reimpresión corregida de la primera edición, 1966) y la traducción la de Schmidt Osmanczik, 2001. 49 - Cf. Hamesse, 1974 , p. 151, no 137.

50 - Cf. Ruiz Arzallus, 1996, 266. En 268 se explica, además, que estas colecciones eran sobre todo utilizadas como material de apoyo a la lectio que el profesor impartía a sus alumnos, entre los cuales es esperable que circularan copias de no muy buena calidad. 
había comenzado su formación en el real Monasterio de San Salvador, situado junto a su pueblo natal, había completado ésta en la entonces muy prestigiosa Universidad de Salamanca, donde hizo los estudios de Bachiller en Artes y de Bachiller en Teología ${ }^{51}$. Nada extraño hay en suponer que Axular conociera esta colección (u otra similar) y que supiera que la idea del tiempo aristotélica estaba ampliamente difundida entre los letrados de su época. En segundo lugar, constatamos que el rechazar una idea pagana que contradecía la que aparecía en los textos religiosos responde a la perfección, como arriba hemos apuntado, a la preceptiva emanada de la Iglesia para la lectura de los clásicos. Por último, no podemos dejar de mencionar que Axular, como Salaberri demuestra a lo largo de todo el trabajo ${ }^{52}$ que dedica a Después, era un buen conocedor de la preceptiva retórica, de manera que, a las razones antes apuntadas, deberíamos sumar el importante efecto de amplificación que sabía que conseguiría rechazando a una autoridad como Aristóteles.

\section{Recapitulación}

Las citas de Aristóteles que aparecen en Después son en general correctas; pertenecen todas a las obras a las que se adjudican y sólo en un caso hay error en la cita del número de libro (cita de la Política de la página 425, que pertenece al VI y no al V) y otro en la del número de capítulo (cita también de Política, página 401, que se encuentra en el 9 y no en el 1). Sin embargo, de esta corrección en la mayoría de las referencias no se puede concluir, como sucedía con las de carácter religioso, que Axular tuviera acceso directo a las obras que cita.

A lo largo de nuestro análisis hemos comprobado que sólo una cita reproduce palabras muy cercanas a las del propio Aristóteles, precisamente en el caso de la Física, de la que se toma una definición. Pero en los demás casos, o bien aparece algún hecho que se menciona en las obras del estagirita ("bien hicieron los antiguos poetas casando a Marte con Venus", página 401; "es bueno para desterrar y suprimir del Estado la holgazanería, y para preservar a los pueblos de levantarse contra su rey o contra otros, el emprender algunas obras grandiosas, el construir ciertas torres o castillos y ocupar en ello a la gente", p. 23), o bien alguna consecuencia extraíble de ellas o bien son un resumen de ideas que en ellas aparecen ("No por una vez, sino repitiendo con frecuencia y muchas veces es como se adquiere la soltura y la costumbre", p. 99; "todas las cosas que viven tienen su medida y su magnitud y también su pequeñez", p. 129). Estas últimas han quedado, en realidad, reducidas a la expresión de verdades generales, de todos admitidas y por todos aceptadas y, contaban, por tanto, con una posibilidad muy alta de ser citadas en los más variados contextos.

Además, todas estas citas, que siempre están fuera de los contextos en que las usaba el estagirita, no son portadoras de ninguno de los datos que en ellas aparecían referidos a la cultura griega; estos datos han sido por lo general eliminados, si bien en alguna ocasión están presentes, pero disfrazados bajo el

51 - Cf. I. Mitxelena, 1977, 57-69. Sobre el ambiente cultural que pudo encontrar allí, cf. Salaberri, 1997, 263-264

52 - Salaberri, 1997. 
manto de la generalización ("el primer mitólogo"= al poeta Homero: los primeros poetas", p. 401), la cristianización (Marte se casó con Venus, p. 401) o la adaptación anacrónica (el tirano pasa a ser rey, las construcciones de edificios desconocidas, castillos, p. 23). En todo caso, resulta evidente que la civilización que había producido estos textos no formaba parte en absoluto ni del acervo cultural del escritor ni del de los destinatarios de su obra ${ }^{53}$.

Hemos de concluir, por tanto, que para adaptarse a los textos de destino las citas de los autores clásicos por un lado habían sido desprovistas de toda su especificidad, de todo lo que las hacía expresiones de un mundo particular y concreto, y por otro que habían sido sometidas a un proceso de remodelación al mundo contemporáneo que incluía la adaptación de sus contenidos a las nuevas realidades y, por supuesto, su cristianización ${ }^{54}$. Así transformadas, podían ser utilizadas en los más variados textos, en los que cumplían la función retórica de apoyar las ideas que en ellos aparecían. Esta capacidad contribuye a explicar su masiva presencia en los textos del siglo XVII, particularmente en los doctrinales, en los que la eficacia en la transmisión del mensaje y no la originalidad era el valor más buscado ${ }^{55}$.

\section{Bibliografia}

- Aldekoa, Iñaki, Historia de la literatura vasca, Donostia, Erein, 2004.

— Añibarro, Fr. Pedro Antonio, Gueroco guero, Edizio kritikoa: Blanca Urgell Lázaro, Bilbao, Real Academia de la Lengua Vasca/Euskaltzaindia, 2001.

- Arcocha-Scarcia, Aurelia, "Géotemporalité de l'enfer dans le Gvero de Pedro de Axular", Lapurdum VI, 2001, 95-104.

- Aristóteles, De anima, W. D. Ross (ed.), Oxford, Clarendon Press, 1961 (reimpresión de 1967).

- Aristóteles, Política, Introducción, traducción y notas de Manuela García Valdés, Madrid, Gredos, 1988.

53 - Por ello, tras el análisis de las citas de los autores clásicos que aparecen en Axular (entre los que no incluye las de Aristóteles), Salaberri concluye que todas ellas comparten dos características, (1) pertenecer en general al acervo de los tópicos universales de la literatura y ser, por tanto, muy conocidas y fáciles de encontrar; y (2) condensar mensajes filosóficos que aparecen en otros textos; Salaberri, 1997, 294-295.

54 - Como Salaberri apunta $(1997,295$ y 303) el hecho de que la mayoría de las citas de los clásicos aparezcan demasiado "fosilizadas" induce a pensar que la remodelación que muestran en esta época y en el propio Axular sea antigua y no debida a este autor.

55 - Es evidente que el problema de la originalidad de las obras de esta época no puede ser planteado desde concepciones actuales. En el caso de Axular ha sido un tema repetidamente tratado por Villasante, en 1972, 132-158 y en 1974, 31-32, donde apunta que en su caso la originalidad consiste en haber concebido y pensado él mismo su libro y en haber sabido plasmarlo y realizarlo con éxito de cara a sus destinatarios. Aldekoa, 2004, 57, aborda el tema con una cita de Francisco de Sales, según la cual en su Introducción a la vida devota ofrece a sus lectores "las mismas flores, pero en diferente ramillete, a causa de la diversa manera de combinarlas". Esa sería también la originalidad de Axular, cuya prosa ascética, que tenía como principal objetivo la salvación de las almas, estaría guiada por el sentido didáctico y utilitario. 
— Aristóteles, Politica, W. D. Roos (ed.), Oxford, Clarendon Press, 1957 (reimpresión de 1967).

- Aristóteles, Ethica Eudemia, F. Susemihl (ed.), Lepizig, Teubner, 1984 y Ámsterdam, Hakkert, 1967.

- Aristóteles, Ethica Nicomachea, I. Bywater, Oxford, Clarendon Press, 1894 (reimpresión de 1962).

- Aristóteles, Physica, W. D. Ross (ed.), Oxford, Clarendon Press, 1950 (reimpresión corregida de la primera edición, 1966).

— Aristóteles, Física, Traducción y notas de Ute Schmidt Osmanczik, Introducción de Antonio Marino López, México D. F., Universidad Nacional Autónoma de México, 2001.

- Aristóteles, Ética nicomáquea. Ética Eudemia, Introducción por Emilio Lledó Iñigo; traducción y notas por Julio Pallí Bonet, Madrid, Gredos, 1988.

- Aristóteles, Acerca del alma, Introducción, traducción y notas de Tomás Calvo Martínez, Madrid, Gredos, 1978.

- Axular Navarrois, Pierre d', Guero, Reprod. facs. de la ed. De Bordelen, G. Milanges, 1643, Bilbao, Euskaltzaindia, 1988.

- Pedro Axular, Gero (Después), Sarrera, Argitalpena eta itzulpena: Aita Luis Villasante, Apaingarriak: Joxe Mari Telleria, Oñati, Jakin, 1976.

- Axular, Després, Introducció: Jean Haritschelhar, Traducció: Daniel Luján, Barcelona, Facultat de Teologia de Catalunya, Fundació Enciclopedia Catalana, 2001.

- Bilbao Telletxea, Gidor, "'Eztut jeusic neure baitharic ekharri, ez eta ere autoretan causitcen ezten gauçaric isquiribatu': Etxeberri Sarakoaren asmatzelanerako iturriak", Anuario del Seminario de Filología Vasca "Julio Urquijo", 2006, 161-120.

- Granada, Luis de, Retórica Eclesiástica o de la manera de predicar, in Obras del V. P. M. Fray Luis de Granada, III, Madrid, Imprenta de la Publicidad (BAE IX), 1945, 488-642.

- J. Hamesse (ed.), Les "Auctoritates Aristotelis". Un florilège médiéval. Étude bistorique et édition critique, Louvain / Paris, Publications Universitaires y BéatriceNauwelaerts, 1974.

— Lafitte, Pierre, "Les citations d'Axular", in A.A., Axular 1643-1943 (Troisième Centenaire du Guero), 38-39.

— López Poza, Sagrario, "Florilegios, polianteas, repertorios de sentencias y lugares comunes. Aproximación bibliográfica", Criticón (49), 1990, 61-76.

- Mangel, Alberto, Una historia de la lectura, traducción de José Luis López Muñoz, Madrid, Alianza Ensayo, 2005 (cuarta reimpresión de la primera edición en castellano de A History of Reading, Knopf Canada, Toronto, 1996).

- Mitxelena, Luis, "Descubrimiento y redescubrimiento en textos vascos", FLV 3, 149-169. 
- Mitxelena Martínez de Ilárduya, Itziar, "Sobre la estancia de Axular en la Universidad de Salamanca, FLV XVI (1974), 85-88.

— Mitxelena Martínez de Ilárduya, Itziar, "Axularren titulua", FLV 25 (1977), 57-68.

— Orpustan, Jean-Baptiste, Précis d'Histoire Littéraire basque, Baigorri, Izpegi, 1996.

- Oyharçabal, Bernard, "Statut et évolution des lettres basques durant les XVII et XVIII" siècles", Lapurdum VI, 2001, 219-287.

- Redondo Moyano, Elena, "Êthos y páthos: los recursos psicológicos para la persuasión en fuentes retóricas griegas", en Retórica y Comunicación. Fuentes antiguas y usos actuales, G. Lopetegui Semperena, M. Muñoz García de Iturrospe y E. Redondo Moyano (editoras), Bilbao, Servicio Editorial de la UPV/EHU, 2006, 25-72.

- Ruiz Arzalluz, Iñigo, "El mundo intelectual del 'antiguo autor': las «Auctoritates Aristotelis» en la «Celestina» primitiva", Boletín de la Real Academia Española, tomo LXXVI, Cuaderno XXIXIX (septiembre-diciembre de 1996), 265-284.

— Salaberri Muñoa, Patxi, Axularren prosa erretorikaren argitan, UPV/EHU, 1997.

- Salaberri Muñoa, Patxi, Haizkora zubaitzaren erroari kheinatzean, Iruña, Pamiela, 2000.

- Urquijo, Julio de, Una fuente del Guero (Axular imitador de Fr. Luis de Granada), Saint Jean de Luz, Dargains, 1912.

- Urquizu, Patricio (dir.), Historia de la literatura vasca, Madrid, Universidad Nacional de Educación a distancia, 2000.

- Villasante, Luis, "Características de la obra "GERO", de Pedro de Axular, FLV XVI, 29-38.

— Villasante, Luis, Axular: mendea, gizona, liburua, Arantzazu, 1972. 